UCRL-ID-127872

\title{
Table-Top Transient Collisional Excitation X-ray Laser Research at LLNL: Status June 1997
}

J. Dunn, A. L. Osterheld, R. Shepherd, W. E. White, V. N. Shlyaptsev, R. E. Stewart

July 8,1997

This is an informal report intended primarily for internal or limited external distribution. The opinions and conclusions stated are those of the author and may or may not be those of the Laboratory.

Work performed under the auspices of the U.S. Department of Energy by the Lawrence Livermore National Laboratory under Contract W-7405-Eng-48. 


\section{DISCLAIMER}

This document was prepared as an account of work sponsored by an agency of the United States Government. Neither the United States Government nor the University of California nor any of their employees, makes any warranty, express or implied, or assumes any legal liability or responsibility for the accuracy, completeness, or usefulness of any information, apparatus, product, or process disclosed, or represents that its use would not infringe privately owned rights. Reference herein to any specific commercial product, process, or service by trade name, trademark, manufacturer, or otherwise, does not necessarily constitute or imply its endorsement, recommendation, or favoring by the United States Government or the University of California. The views and opinions of authors expressed herein do not necessarily state or reflect those of the United States Government or the University of California, and shall not be used for advertising or product endorsement purposes.

This report has been reproduced directly from the best available copy.

Available to DOE and DOE contractors from the Office of Scientific and Technical Information

P.O. Box 62, Oak Ridge, TN 37831

Prices available from (615) 576-8401, FTS 626-8401

Available to the public from the

National Technical Information Service

U.S. Department of Commerce

5285 Port Royal Rd.,

Springfield, VA 22161 


\title{
Table-Top Transient Collisional Excitation X-ray Laser Research at LLNL: Status June 1997
}

\author{
J. Dunn, A.L. Osterheld, R. Shepherd, \\ W.E. White, V.N. Shlyaptsev 1 , and R.E. Stewart \\ Lawrence Livermore National Laboratory, Livermore, CA 94550 USA \\ 1 Permanent Address: P.N. Lebedev Physical Institute, Leninsky Prospect 53, Moscow Russia
}

\begin{abstract}
This is a status report of transient collisional excitation $x$-ray laser experiments at LLNL during June 1997 that have the advantage of being conducted on a table-top. Two laser drivers with modest energy $\sim 6 \mathrm{~J}$ are used in the scheme: a long $\sim 1$ ns pulse to preform and ionize the plasma followed by a short $\sim 1$ ps pulse to produce the excitation and population inversion. The beams are co-propagated and focused using a combination of a cylindrical lens and paraboloid to a line of $\sim 70 \mu \mathrm{m} \times 12.5 \mathrm{~mm}$ dimensions. High repetition rates approaching 1 shot $/ 3 \mathrm{~min}$. allow typically in excess of 50 target shots in a day. Various slab targets have been irradiated and we report preliminary results for $\mathrm{x}$-ray laser gain in $3 p-3 s \mathrm{~J}=0-1 \mathrm{Ne}$-like Ti and $\mathrm{Fe}$ transitions where gains as high as $24 \mathrm{~cm}^{-1}$ and $g L$ products of $\sim 15$ have been observed.
\end{abstract}

\section{INTRODUCTION}

The first laboratory demonstration of laser-driven collisional excitation $x$-ray lasers was reported by Matthews et al 1 in 1984 for Ne-like Se at $\sim 200 \AA$. Subsequently, collisional excitation has been shown to work on many different Ne-like materials as well as Ni-like schemes and has been extended to $\sim 35 \AA$ wavelength within the water window, for example overview by MacGowan et al ${ }^{2}$, review by Keane ${ }^{3}$. These schemes require large laser facilities to produce driver energies of $100 \mathrm{~J}$ to a few kilojoules. In addition, the shortest $\mathrm{x}$-ray laser duration so far demonstrated on a collisional x-ray laser has been $45 \mathrm{ps}$ (Da Silva et al ${ }^{4}$ ).

Recently Shlyaptsev et al 5 have described the transient collisional excitation scheme where a population inversion can be achieved on a timescale of a picosecond to produce a high gain, high efficiency $\mathrm{x}$-ray laser based on Ne-like or Ni-like systems. This technique requires two stages where a long $\sim 1 \mathrm{~ns}$ pulse laser at $10^{12} \mathrm{~W} \mathrm{~cm}^{-2}$ and short $\sim 1$ ps pulse at $10^{15} \mathrm{~W} \mathrm{~cm}^{-2}$ are used to irradiate a solid target. The long pulse forms a long scale length plasma at the correct ionization but low electron temperature. The short pulse heats the plasma electron temperature to $\sim 1 \mathrm{keV}$ or higher in a few picoseconds. Rapid collisional excitation leads to a population inversion in the $n=3$ levels where gains as high as $100 \mathrm{~cm}^{-1}$ are predicted. To utilize this high gain refraction due to plasma density gradients must be minimized 6 . Since the excitation essential for gain is produced by the short pulse this leads to a number of advantages: (1) the x-ray laser output will be short duration < $30 \mathrm{ps}$; (2) there is a reduced need for Nova class lasers. In fact a table-top, chirped pulse amplification (CPA) $\sim 1$ ps laser driver ${ }^{7}$ with a few joules delivered in a line focus of $\sim 1 \mathrm{~cm}$ can potentially produce an $\mathrm{x}$-ray laser close to saturation. 
Nickles et al 8,9 have proved the transient collisional excitation scheme experimentally by measuring gain $\sim 19 \mathrm{~cm}^{-1}$ on the $3 p-3 s \mathrm{~J}=0-1 \mathrm{Ne}$-like Ti transition at $326 \AA$ for a line focus up to $5 \mathrm{~mm}$. This research was performed on a table-top laser facilty producing $7 \mathrm{~J}$ of long $\sim 1.5 \mathrm{~ns}$ pulse and $4 \mathrm{~J}$ of short pulse 0.7 ps energy at the Max Born Institute (MBI) in Berlin, Germany. Collaborating with the Rutherford Appleton Laboratory (Kalashnikov 10), the MBI group have repeated high gain results on $\mathrm{Ti}$ and $\mathrm{Ge}$ using the larger CPA Vulcan laser.

We report activities starting in calendar 1997 to investigate transient collisional excitation schemes using the Physics and Space Technology Directorate Janus and Janus-ps laser facilities. We have observed high gain $24 \mathrm{~cm}^{-1}$ on Ne-like Ti $n=3-3$ transitions at $301 \AA, 326 \AA$. We have also observed transient collisional excitation on Ne-like Fe at $255 \AA$ for the first time. We describe the experimental setup and give a few preliminary results to demonstrate the technique.

\section{EXPERIMENTAL DESCRIPTION}

The two pulses needed for this $\mathrm{x}$-ray laser scheme are produced by the East arm of Janus 800 ps (FWHM), $1064 \mathrm{~nm}$ wavelength at rod energies and the table-top Janus-1ps laser. The lasers are capable of producing typically $\sim 6 \mathrm{~J}$ each on target at a repetition rate of $1 \mathrm{shot} / 3 \mathrm{~min}$. as indicated in Table 1. The Janus-1ps laser is a hybrid CPA system based on a Ti:Sapphire oscillator and regenerative amplifier front end tuned to $1053 \mathrm{~nm}$ wavelength with Nd:phosphate glass power amplifiers. It has been described in detail elsewhere ${ }^{11}$. The oscillator, pulse stretcher, regenerative amplifier, and high power amplifiers with laser diagnostics occupy two $4^{\prime} \times 12^{\prime}$ laser tables. Currently, $7 \mathrm{~mm}, 16 \mathrm{~mm}, 25 \mathrm{~mm}$ and $50 \mathrm{~mm}$ diameter amplifier rods produce $10 \mathrm{~J}$ of energy prior to compression. After amplification, the beam is enlarged to $8 \mathrm{~cm}$ diameter and is recompressed in the vacuum grating compressor (dimensions $2.5^{\prime} \times 4^{\prime} \times 12^{\prime}$ ) to $500 \mathrm{fs}$ (FWHM) with a sech $^{2}$ pulse shape. Laser parameters including energy, temporal shapes and relative timing, near field image, focal spot and spectrum are monitored on every shot. The system also has the flexibility of producing long pulses up to $\sim 5 \mathrm{~ns}$ and lengthening the short pulse duration by de-tuning the compressor gratings. For this experiment $\sim 1.5 \mathrm{ps}$ pulse (FWHM) was used. The short pulse beam path is enclosed in vacuum from compressor to target chamber.

The Janus long pulse is combined with the short pulse beam after compression in a copropagating geometry by means of a polarizer. The beams are relayed into the target chamber by steering mirrors. A line focus $25-120 \mu \mathrm{m}$ wide $\times 12.5 \mathrm{~mm}$ length (variable width but fixed length) is formed using a combination of a concave $400 \mathrm{~cm}$ focal length, $10 \mathrm{~cm}$ diameter cylindrical lens and a gold-coated $61 \mathrm{~cm}$ focal length, $15 \mathrm{~cm}$ diameter on-axis paraboloid. A $5 \mu \mathrm{m}$ thick nitrocellulose debris shield protects the paraboloid from target debris. B-integral effects due to the transmission of the short pulse through the cylindrical lens are not significant for this power density. The focus and beam alignment are achieved by lowering the target and using a crossed cylindrical lens microscope on the laser optical axis with different magnification for the length and width. At this stage the final overlap of the two co-propagating beams is adjusted to better than $5 \mu \mathrm{m}$. Polished slab targets capable of $40-200$ laser shots are mounted in a precision target holder. Normal incidence is established at installation with an alignment laser. Target placement can be adjusted under vacuum with a numerical readout 4-axis target positioner. A $40 \times$ telescope mounted transverse to the laser focusing axis is useful for positioning the target relative to the collection optics of the flat-field spectrometer. 
The main diagnostic for the $\mathrm{x}$-ray laser lines looking on-axis is a1200 line $\mathrm{mm}^{-1}$ flat-field grating spectrometer a with back-thinned $1024 \times 1024 \mathrm{CCD}$ detector to cover $150-350 \AA$. A Au mirror collection optic images the plasma gain region with $1: 1$ magnification onto a $100 \mu \mathrm{m}$ wide entrance slit. Additional instruments include a CCD x-ray slit camera with $25 \mu \mathrm{m}$ spatial resolution for line focus uniformity and a CCD flat crystal KAP $(001), 2 \mathrm{~d}=26.58 \AA$, spectrometer to monitor the ionization in the $n=3-2,4-2$ Ne-like resonance lines. Time-resolved diagnostics were not fielded at this stage. All CCD detector systems are LLNL designed and fabricated 12,13 which allows real-time data acquisition within 15 seconds of the laser shot.

The table-top $x$-ray laser experimental activities which included running the $x$-ray diagnostics, acquiring the data, target positioning, focusing, aligning and operating the laser with optical diagnostics were typically performed by two individuals.

\section{EXPERIMENTAL RESULTS}

Figure 1 shows a simplified energy level diagram for the $n=3$ levels of Ne-like titanium. The transient collisionally pumped $\mathrm{x}$-ray laser is predicted to work in the $n=3$ excited levels, specifically the $3 p-3 s J=0-1$ line at $326 \AA$. Strong monopole pumping from the ground state populates the upper $3 p$ level; the population inversion is maintained by the fast radiative decay from the lower $3 s$ level to the $2 p^{6}$ ground state. A second transition, $3 d-3 p$ at $301 \AA$, is expected to have gain as described recently by Nilsen 6 . The upper level is populated by a combination of collisional excitation and self-photopumping by the intense $3 d-2 p$ resonance line at $23.349 \AA$. The lower level requires collisional de-excitation to adjacent $n=3$ levels to maintain the population inversion. The first evidence of $x$-ray lasing on the LLNL table-top system was observed for a polished titanium slab target on 3rd June 1997. This data is shown on the spectral image and lineout of Figure 2(a) and (b), respectively. The intense $3 p-3 s$ line is identified at $326 \AA$. By optimizing conditions for gain and plasma length, the output of this line is routinely two orders of magnitude higher than shown in Fig. 2(b). An additional weaker line at $301 \AA$ has been identified as the $3 d-3 p$ line. Generally, this output is around 5\% of the stronger line. However, conditions can be adjusted to increase the intensity to $50 \%$ of the stronger line.

We have characterized the dependence of the $x$-ray laser output as a function of different controllable parameters which include incident laser energy, the temporal separation of the two pulses, short pulse duration and the laser focal width. Using an optical streak camera to monitor the relative timing of the laser pulses, as illustrated in Figure 3(a), we have found that the Ti Xray laser output is strongly dependent on the delay of the short pulse relative to the long pulse. As shown in Figure 3(b) an optimum time window exists at -1.6 ns for strong $3 p-3 s$ intensity.

A single piece of polished titanium slab with different lengths varying from $1 \mathrm{~mm}$ to $10 \mathrm{~mm}$ was irradiated in order to estimate the gain on the $326 \AA 3 p-3 s$ transition. A preliminary sample of this data is shown in Figures 4. (a) and (b). The spectrum for three target lengths 2,3 and $5 \mathrm{~mm}$ is plotted, Figure 4 (a). The exponential output for the $326 \AA$ line as a function of length is clearly visible. Note that the intensity scale for the $5 \mathrm{~mm}$ spectrum is labeled on the right hand side of the plot and is $10 \times$ higher than the $2,3 \mathrm{~mm}$ spectrum labeled on the left side. A selected data set, where the irradiation conditions were very similar is plotted in Figure 4 (b) to show $x$ ray laser intensity as a function of target length. $\mathrm{X}$-ray laser output is observed for $1 \mathrm{~mm}$ target lengths. The $326 \AA 3 p-3 s$ intensity is fitted for 1 to $5 \mathrm{~mm}$ target lengths. using the Linford 
equation 14 for unsaturated gain; $g \sim 24 \mathrm{~cm}^{-1}$ is deduced for up to $5 \mathrm{~mm}$ lengths. The roll-off in the x-ray laser output for longer target lengths is beyond the scope of this report but $g L$ product of $\sim 15$ has been demonstrated for titanium. Figure 5 illustrates that intense $x$-ray laser output at a shorter wavelength can be generated on higher $Z$ materials under similar irradiation conditions for this transient $\mathrm{x}$-ray laser scheme. A polished iron slab $8.5 \mathrm{~mm}$ long irradiated with $6 \mathrm{~J}$ long pulse and $5 \mathrm{~J}$ of short pulse can be made to strongly lase on the $3 p-3 s$ transition at $255 \AA$.

\section{SUMMARY}

In conclusion, we have configured the Janus-ps laser in conjunction with the East arm of Janus at rod shot energies to produce a line focus as an $\mathrm{x}$-ray laser driver at table-top energies. Intense $\mathrm{x}$-ray laser emission has been produced for $n=3-3$ transitions at $326 \AA$ and $255 \AA$ fron $\mathrm{Ne}$-like Ti and Fe, respectively. The next step, to be implemented in July/August 1997, is to build the long pulse laser on the same Janus-ps table with energy of $10-15 \mathrm{~J}$ in a $600 \mathrm{ps}$ pulse. We will then have an independent, flexible, table-top (on two $4^{\prime} \times 12^{\prime}$ laser tables) laser driver dedicated to further detailed investigation of transient collisional excitation $\mathrm{x}$-ray lasers.

\section{ACKNOWLEDGMENTS}

We appreciate the excellent technical contributions from J. Hunter, B. Sellick for laser support, D. Swan for assistance with the flat-field spectrometer and A. Ellis for target preparation. Thanks to Mark Eckart for continuing support of this research. This work was performed under the auspices of the U.S. Department of Energy by the Lawrence Livermore National Laboratory under Contract No. W-7405-Eng-48.

\section{REFERENCES}

1. D.L. Matthews et al, Phys. Rev. Lett. 54, 110, (1985).

2. B.J. MacGowan et al, Phys. Fluids B 4, 2326 (1992).

3. C. J. Keane, SPIE proc. 1551, 2 (1991).

4 L.B. Da Silva, R.A. London, B.J. MacGowan, S. Mrowka, D.L. Matthews, and R.S. Craxton, Opt. Lett. 19(19), 1532 (1994).

5. V.N. Shlyaptsev, P.V. Nickles, T. Schlegel, M.P. Kalashnikov, and A.L. Osterheld, SPIE proc. 2012, 111 (1993).

6. J. Nilsen, Phys. Rev. A 55(4), 3271 (1997).

7. D. Strickland and G. Mourou, Opt. Commun. 56, 219 (1985).

8. P.V. Nickles, M. Schnürer, M.P. Kalashnikov, I Will, W. Sandner, and V.N. Shlyaptsev, SPIE proc. 2520, 373 (1995).

9. P.V. Nickles, V.N. Shlyaptsev, M.P. Kalashnikov, M. Schnürer, I Will, and W. Sandner, Phys. Rev. Lett. 78(14), 2748 (1997).

10. M.P. Kalashnikov, private communication (1997).

11. J. Dumn, B.KF. Young, A.K. Hankla, A.D. Conder, W.E. White, and R.E. Stewart, AIP proc. 369, 652 (1996).

12. A. D. Conder, J. Dunn, and B. K. F. Young, Rev. Sci. Instrum. 66 (1) 709 (1995).

13. J. Dunn, B.K.F. Young, A. D. Conder, and R.E. Stewart, SPIE proc. 2654, 119 (1996).

14 G.J Linford, E.R. Peressini, W.R. Sooy, and M.L. Spaeth, Appl. Opt. 13(2), 379 (1974). 
Table 1. Laser Driver and Shot Parameters

Parameter

Long Pulse (1064 nm)

800 ps - 5 ns (FWHM), 6 J EOT

Short Pulse (1053 nm)

500 is - $10 \mathrm{ps}$ (FWHM), $6 \mathrm{~J}$ EOT

Maximum Short Pulse Peak Power

$15 \mathrm{TW}$ (7.5J EOT in $500 \mathrm{fs})$

Beam Diameters

$8 \mathrm{~cm}$

Relative Laser Jitter

$80 \mathrm{ps} \mathrm{ms}$

Line Focus

$25-120 \mu \mathrm{m} \times 12.5 \mathrm{~mm}(\mathrm{~W} \times \mathrm{L})$

Maximum Laser Shot Rate

1 shot/3 minutes

Typical Experimental Shot Rate

1 shot/6 minutes

Typical shots in a week

250 on target 


\section{Ne-like Ti Energy \\ Level Diagram}

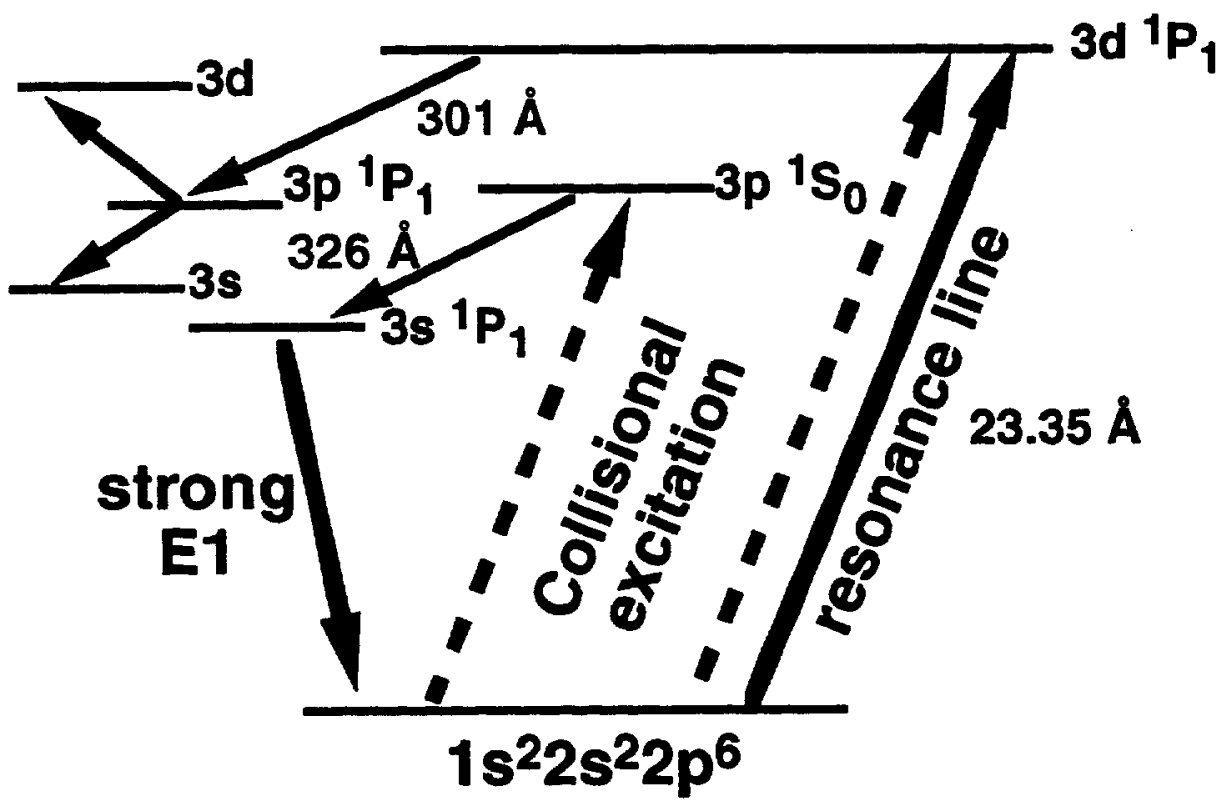

Figure 1 Schematic energy level diagram for Ne-like TI x-ray laser at $326 \AA$ Population of the upper level is driven by strong monopole collisional excltation. $301 \mathrm{~A}$ transition is pumped by combination of collisional excitation and self-photopumping by the $3 d-2 p$ resonance line at $23.35 \AA$. 
(a)

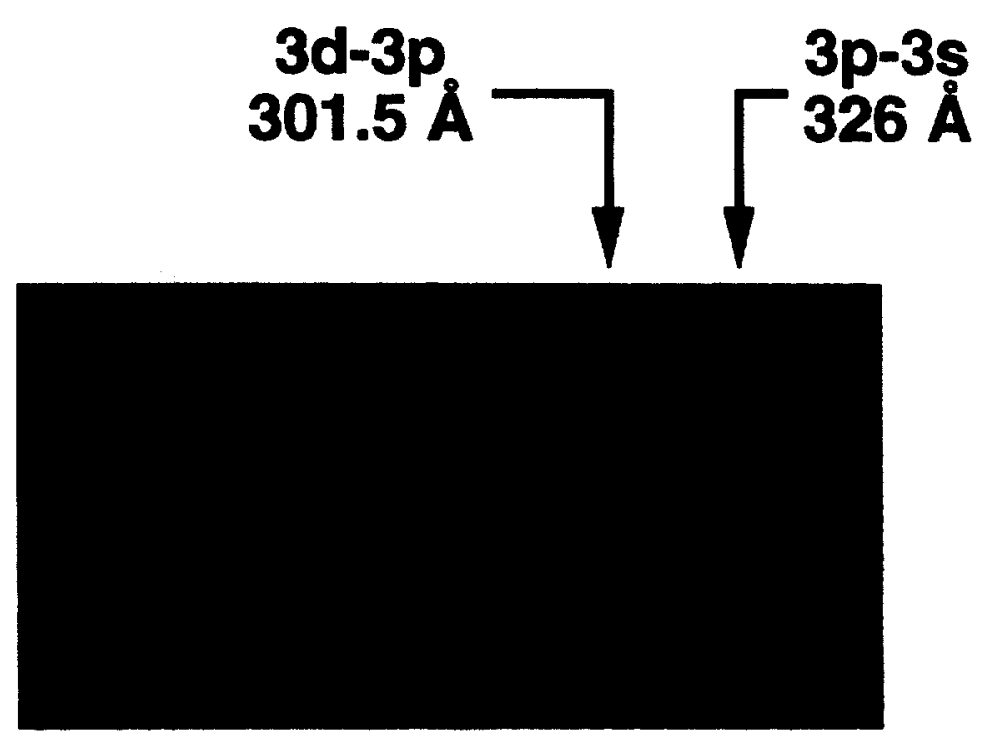

(b)

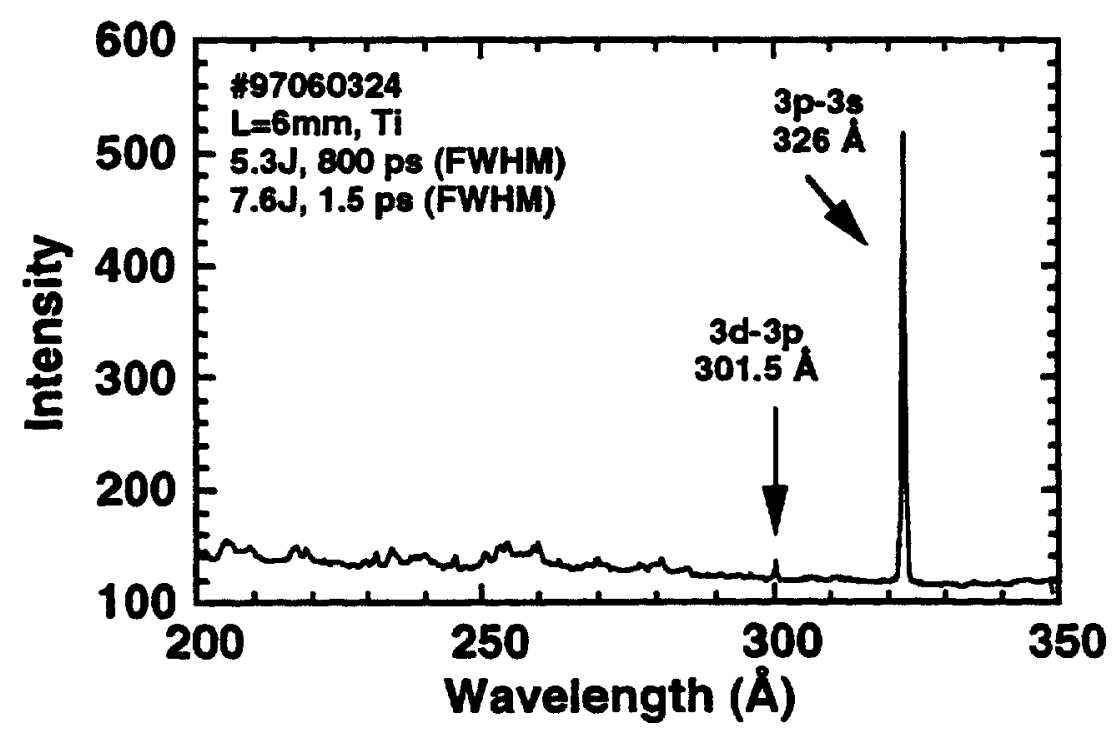

Figure 2 (a) Spectral image showing $x$-ray laser transitions from Nelike Ti line focus plasma. (b) Lineout along wavelength dispersive axis. 326 A line is brightest feature in spectral region. 
(a)

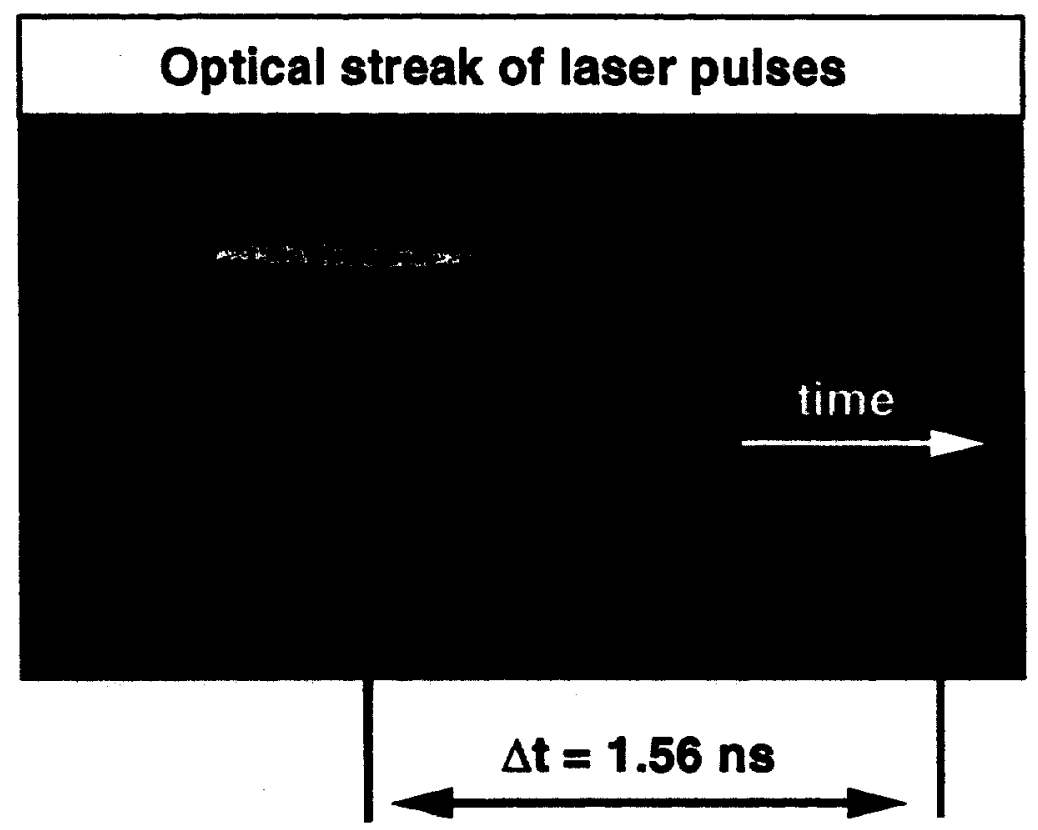

(b)

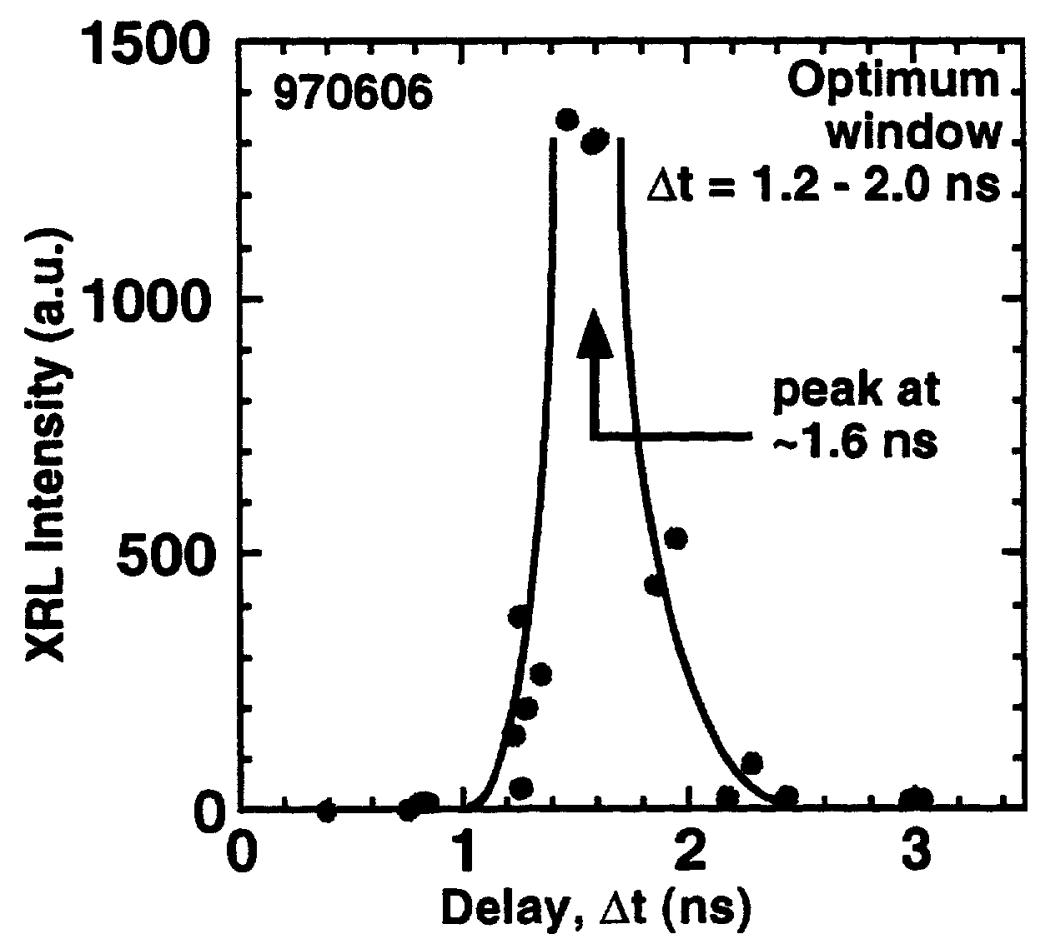

Figure 3 (a) Optical streak image showing relative timing of laser driver pulses. (b) X-ray laser output from Ne-like TI 326 A transition has a strong dependence as a function of the time delay between the short pulse and the long pulse. There is an optimum window for $1.2 \mathrm{~ns}<\Delta \mathrm{t}<2.0 \mathrm{~ns}$ with a strong peak at $\sim 1.6 \mathrm{~ns}$. 
(a)

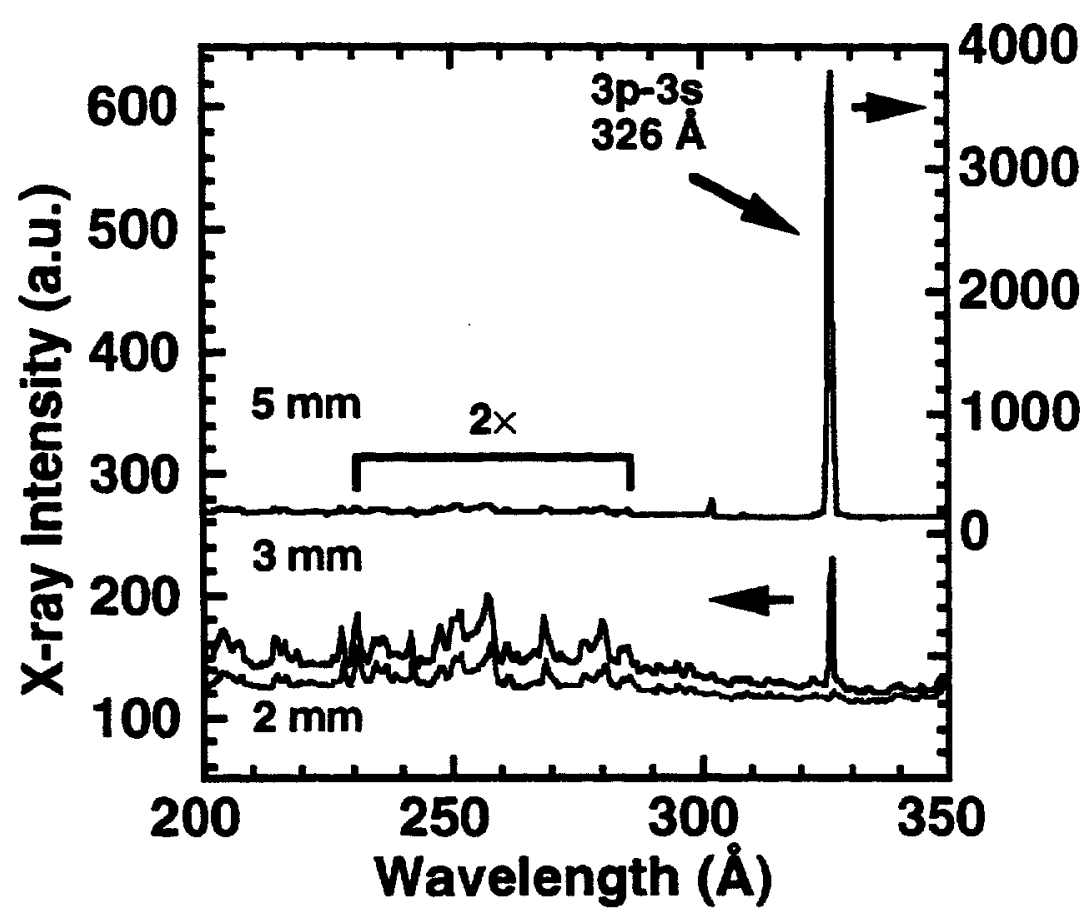

(b)

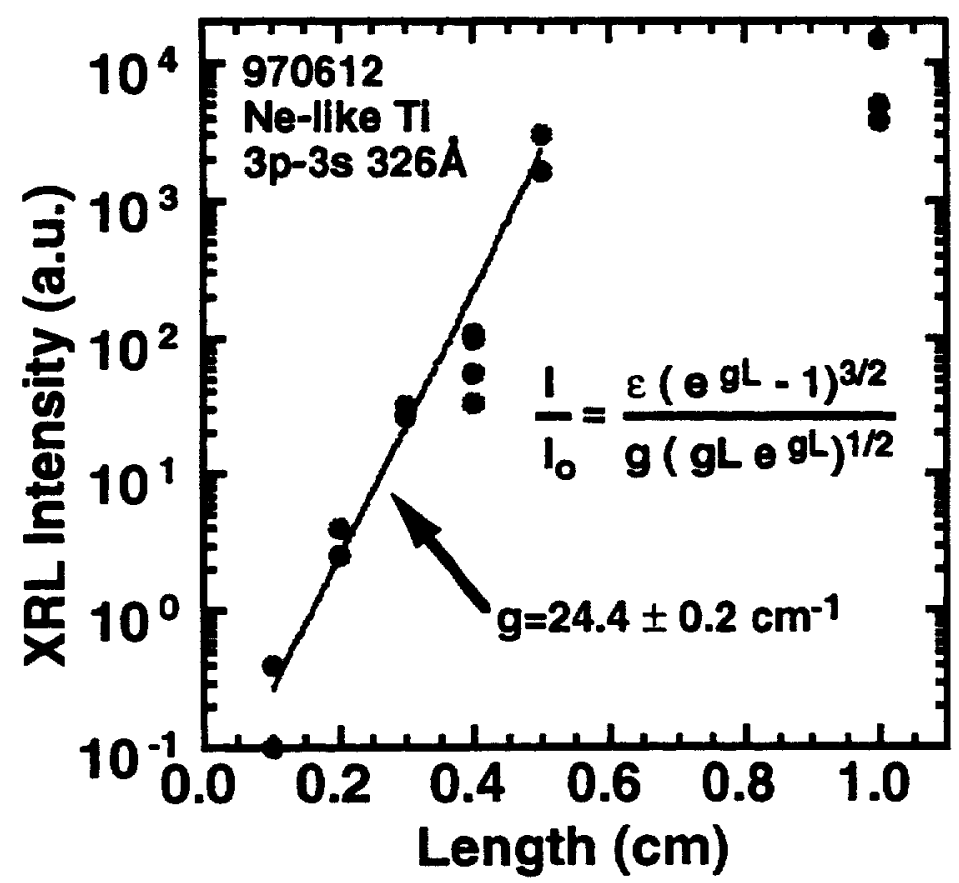

Figure 4 (a) Typical spectra for Ti slab target lengths of 2,3 and $5 \mathrm{~mm}$. The exponential output of the $326 \AA 3 p$-3s Ne-like TI line is clearly visible. Note that the intensity scale (right hand) for the $5 \mathrm{~mm}$ spectrum is $10 \times$ higher than the 2, $3 \mathrm{~mm}$ spectrum (left hand). (b) $X$-ray laser output for $326 \AA$ transition is plotted as a function of length. Estimate gain of $-24 \mathrm{~cm}^{-1}$ for target lengths up to $5 \mathrm{~mm}$. 


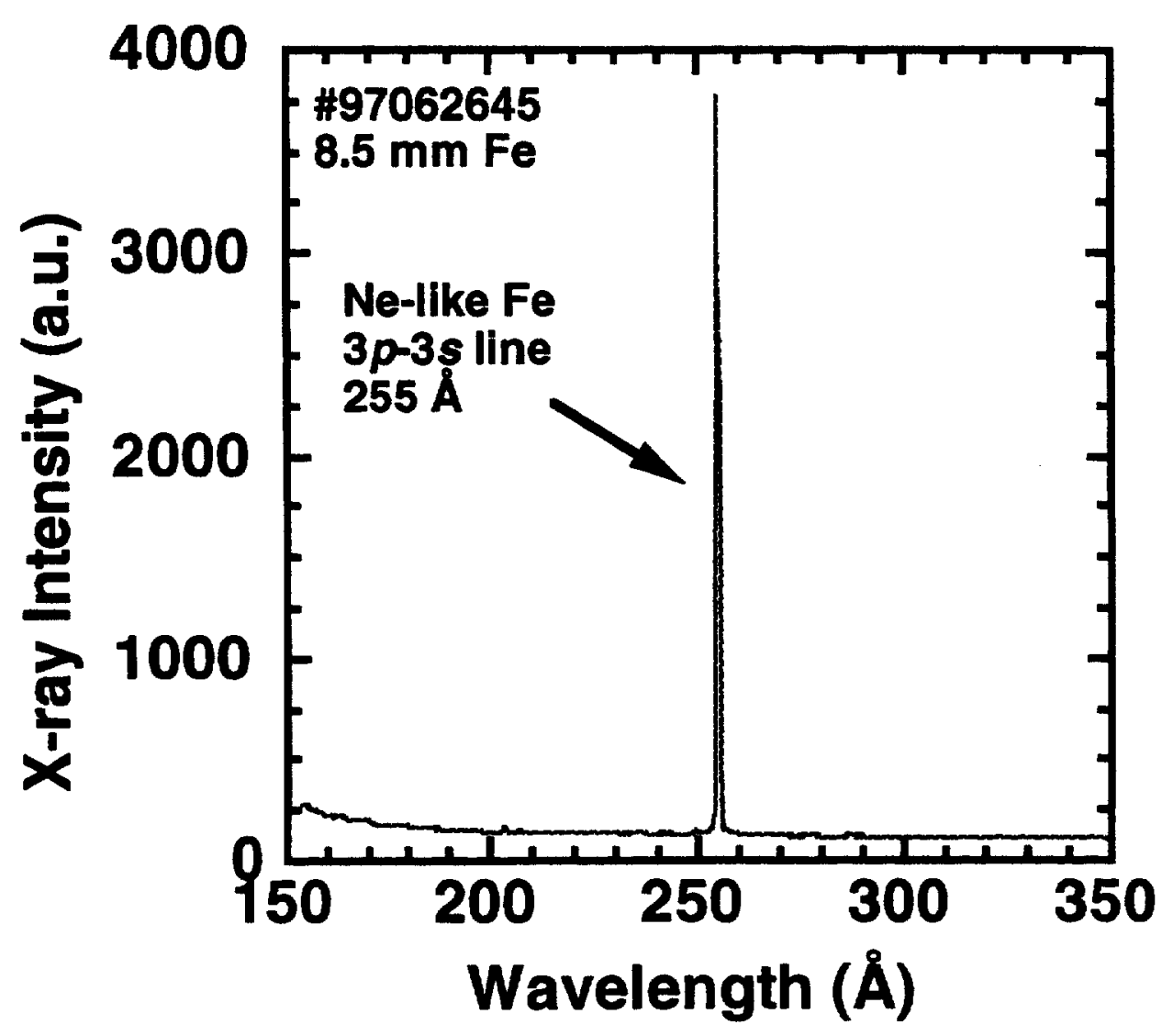

Figure 5 Spectrum from $8.5 \mathrm{~mm}$ Fe slab irradiated by $6 \mathrm{~J}$ of long pulse and $5 \mathrm{~J}$ of short pulse energy. The strong output of the $255 \AA 3 p-3 s$ Ne-llke Fe line is demonstrated for the first time in a transient collisional x-ray laser scheme. 


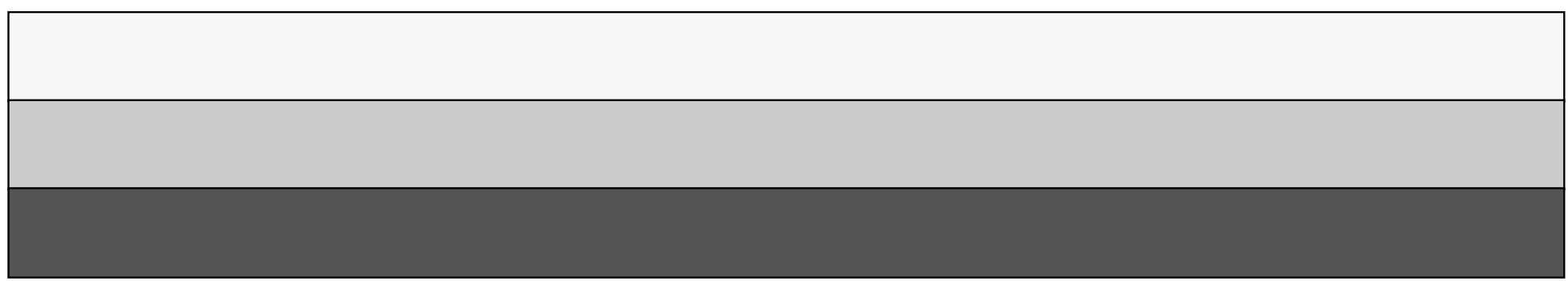

